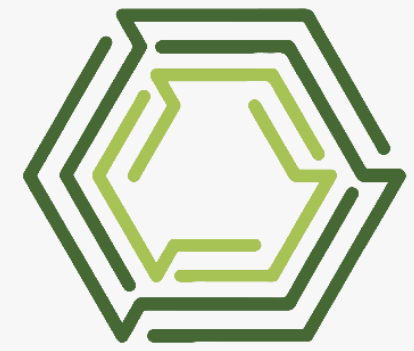

COINTER PDVAgro 2020

V CONGRESSO INTERNACIONAL DAS CIÊNCIAS AGRÁRIAS Edição 100\% virtual | 02 a 05 de dezembro ISSN:2526-7701 | PREFIXO DOI:10.31692/2526-7701

\title{
EFICIÊNCIA E VINGAMENTO DO MARACUJÁ AMARELO (Passiflora edulis Sims) EM DIFERENTES FORMAS DE POLINIZAÇÃO NA REGIÃO DOS COCAIS
}

\section{EFICIENCIA Y VENGANZA DE LA PASIÓN AMARILLA (Passiflora edulis Sims) EN DIFERENTES FORMAS DE POLINIZACIÓN EN LA REGIÓN COCAL}

\section{EFFICIENCY AND REVENGE OF THE YELLOW PASSION FRUIT (Passiflora edulis Sims) IN DIFFERENT POLLINATION FORMS IN THE COCAL REGION}

\author{
Apresentação: Comunicação Oral \\ Maria Iris dos Santos Costa ${ }^{1}$; Franklim de Assis Costa ${ }^{2}$; Marcelo Jonathas Sousa e Sousa ${ }^{3}$; Maria Doroteia \\ Marçal da Silva ${ }^{4}$; Caio Veloso ${ }^{5}$
}

DOI: https://doi.org/10.31692/2526-7701.VICOINTERPDVAgro.0744

\section{RESUMO}

O Brasil é o maior produtor e o maior consumidor mundial de maracujá, a região Nordeste tem liderado a produção brasileira do maracujá amarelo nos últimos anos, sendo responsável por $50 \%$ da produção brasileira, este estudo, nas passifloras, a polinização influencia a frutificação, seja por ação de agentes polinizadores (insetos), seja através da polinização artificial, sendo a diferença do percentual de pegamento pelos dois métodos, portanto o obejetivo geral deste estudo é é avaliar a eficiência do maracujá amarelo por três diferentes formas de polinização: polinização natural ( tratamento 1); polinização artificial usando cotonete (tratamento 2); polinização natural mais artificial (tratamento 3), na região de Codó-Ma, sendo realizado a polinização por esses tês métodos no período de Novembro de 2018 a junho 2019, o locus da pesquisa tem área de $1248 \mathrm{~m}^{2}$, pomar com seis meses de desenvolvimento através da condução espaldeira vertical com espaçamento de $4 \mathrm{~cm}$ entre fileiras e $3 \mathrm{~cm}$ entre plantas e irrigação por gotejamento o inseto polinizador envolve mamangavas presente no pomar e os resultados e conclusão encontrados foram para maior formação de frutos o tratamento 2, polinização artificial teve o melhor resultado seguido do tratamento 3 e depois tratamento 1 e no total foram avaliadas 54 plantas de maracujá amarelo.

Palavras-Chave: Polinização, Pomar, mamangavas

\section{RESUMEN}

Brasil es el mayor productor y mayor consumidor mundial de maracuyá, la región Nordeste ha liderado la producción brasileña de maracuyá amarilla en los últimos años, representando el $50 \%$ de la producción brasileña, este estudio, en pasifloras, la polinización influye en la fructificación, ya sea por la acción de agentes polinizadores (insectos), o mediante polinización artificial, la diferencia en el

\footnotetext{
${ }^{1}$ Agronomia, IFMA campus Codó, santosiriscosta@ gmail.com

${ }^{2}$ Agronomia, IFMA campus Codó, marceloengeagro@outlook.com

${ }^{3}$ Ciências agrárias, IFMA campus Codó, franklimassis@ @otmail.com

${ }^{4}$ Mestre agronomia, IFMA, mariadoroteia.silva@ifma.edu.br

${ }^{5}$ Mestre biologia, IFMA, caio.veloso@ifma.edu.br
} 
porcentaje de captura por los dos métodos, por lo que el objetivo general de este estudio es evaluar la eficiencia de la maracuyá amarilla mediante tres formas diferentes de polinización: polinización natural (tratamiento 1); polinización artificial con hisopo de algodón (tratamiento 2); más polinización natural artificial (tratamiento 3), en la región de Codó-Ma, siendo polinizado por estos tres métodos desde noviembre de 2018 a junio de 2019, el locus de investigación tiene un área de $1248 \mathrm{~m}^{\wedge} 2$, huerto con seis meses de desarrollo por conducción esparcidor vertical con espaciamiento de $4 \mathrm{~cm}$ entre hileras y $3 \mathrm{~cm}$ entre plantas y riego por goteo el insecto polinizador involucra abejorros presentes en el huerto y los resultados y conclusión encontrados fueron para mayor formación de frutos el tratamiento 2, polinización artificial tuvo se evaluó el mejor resultado seguido del tratamiento 3 y luego el tratamiento 1 y un total de 54 plantas de maracuyá amarilla.

Palabras clave: polinización, huerto, abejorros

\section{SUMMARY}

Brazil is the largest producer and the world's largest consumer of passion fruit, the Northeast region has led the Brazilian production of yellow passion fruit in recent years, accounting for $50 \%$ of Brazilian production, this study, in passifloras, pollination influences fruiting, either by the action of pollinating agents (insects), or through artificial pollination, the difference in the percentage of catching by the two methods, so the general objective of this study is to evaluate the efficiency of yellow passion fruit by three different forms of pollination: natural pollination (treatment 1); artificial pollination using cotton swab (treatment 2); more artificial natural pollination (treatment 3), in the Codó-Ma region, being pollinated by these three methods from November 2018 to June 2019, the research locus has an area of $1248 \mathrm{~m}^{\wedge} 2$, orchard with six months of development through conduction vertical spreader with spacing of $4 \mathrm{~cm}$ between rows and $3 \mathrm{~cm}$ between plants and drip irrigation the pollinating insect involves bumblebees present in the orchard and the results and conclusion found were for greater fruit formation the treatment 2, artificial pollination had the best result followed by treatment 3 and then treatment 1 and a total of 54 yellow passion fruit plants were evaluated.

Keywords: pollination, orchard, bumblebees

\section{INTRODUÇÃO}

O Brasil é o maior produtor e o maior consumidor mundial de maracujá, chegando a produzir, aproximadamente, um milhão de toneladas ao ano (FALEIRO, 2016).

Maracujá é o nome geral dado a várias espécies de Passiflora. Estima-se que o gênero Passiflora possua mais de 500 espécies, a maioria produzindo frutos para consumo in natura e processamento industrial, flores com uma beleza única e grande potencial ornamental, além de apresentar fitoconstituintes em diferentes partes da planta que podem ser utilizadas para propriedades medicinais. A maioria das espécies é encontrada na América Tropical, incluindo Brasil, Colômbia, Peru, Equador, Bolívia e Paraguai, embora existam espécies nativas dos Estados Unidos à Argentina, além da Ásia, Austrália e China. Como existem mais de 100 espécies endêmicas no Brasil, o maracujá é considerado parte da biodiversidade brasileira (BERNACCI et al., 2015).

A região Nordeste tem liderado a produção brasileira do maracujá amarelo nos últimos anos, sendo responsável por 50\% da produção brasileira, seguida pelas regiões Sudeste, Norte, Centro-Oeste e Sul. Uma alteração significativa na distribuição geográfica dos pomares tem sido apontada por Gonçalves e Souza (2006): o Pará, que se destacou como principal produtor por alguns anos, cedeu espaço para os pomares da Bahia, Ceará e Espírito Santo, os 3 maiores 
produtores em 2006. O mesmo ocorre em São Paulo, grande produtor do início da década de 90, com área de produção reduzida significativamente, em função da elevada incidência de viroses (MELETTI et al., 2010).

O maracujazeiro é cultivado em pequenas propriedades, a maioria com pomares de 3 a 5 hectares. Embora seja uma cultura de alto risco, devido à grande suscetibilidade a doenças, por utilizar insumos de alto valor aquisitivo e de ser necessário atender à exigência de qualidade dos mercados a que se destina, tem sido uma atividade bastante atrativa, pelo alto valor agregado da produção. (MOLLETI, 2005).

A flor do maracujá é perfeita, porém é alógama, razão pela qual precisa de polinização cruzada (o pólen de uma flor deve ser depositado no estigma de flores de outra planta da mesma espécie). As abelhas são os principais insetos responsáveis por esse transporte de pólen e, no maracujá, esse serviço é realizado por abelhas de grande porte, principalmente as mamangavas do gênero Xylocopa. Assim como as mamangavas, as flores dessa cultura são grandes, podendo chegar a $7 \mathrm{~cm}$ de diâmetro, e produzem néctar em abundância, característica que as torna atraentes aos polinizadores. Um dos aspectos que dificultam a autofecundação é o fato de a flor apresentar um fenômeno conhecido como protandria, ou seja, o pólen fica maduro antes de os estigmas da mesma flor estarem aptos a recebê-lo (CAMILLO, 2003).

Em estudos foi comprovado que a deficiência de polinização representa aproximadamente $24 \%$ da deficiência de produtividade agrícola em pequenas propriedades rurais de até 2 hectares em países em desenvolvimento (FREITAS; BOMFIM, 2017). Um exemplo de produção agrícola dependente de polinização cruzada, é o maracujá (Passiflora edulis) polinizado pelas abelhas mamangavas (Xylocopa) (JUNQUEIRA, 2016).

Recomenda-se fazer a polinização artificial do maracujá em plantios com mais de 10 ha, uma vez que a natural, pelas mamangavas, se torna difícil principalmente nos surtos de grande florada. A polinização artificial é também acomselhada em pequenos plantios , quando a população de mamangavas é pequena.(EMBRAPA, 2006).

No estado do maranhão, a produção de maracujá amarelo ainda é pequena, isso acontece por falta de conhecimento por parte dos produtores produtorese alguns profissionais sem deixar de levar em questão os tratos culturais e, principalmente, a escassez de agentes polinizadores. Assim, a pesquisa em tela poderá informar aos produtores e profissionais em geral sobre a utilização da técnica de polinização manual. Para uma boa produtividade nos pomares do maracujazeiro, faz-se necessário conhecer bem a anatomia da planta, principalmente no requisito desejado, nesse caso a polinização das flores do maracujazeiro e a preservação dos agentes polinizadores destas. 


\section{EFICIÊNCIA E VINGAMENTO DO MARACUJÁ AMARELO}

Destarte, com essa pesquisa será possível ampliar os conhecimentos acerca dos problemas locais, como a queda de flores não polinizadas, por falta da grande demanda na produção na época da florada do maracujazeiro e no tocante ao aumento da produtividade do maracujá amarelo, além da definição de técnicas simples para do desempenho da formação do fruto que possam solucionar tais problemas para a agricultura familiar.

Portanto o objetivo geral desta pesquisa é avaliar a eficiência do maracujá amarelo por três diferentes formas de polinização: polinização natural; polinização artificial (cotonete); polinização natural mais artificial, na região de Codó-MA. e os objetivos específicos são realizar o levantamento da eficiência quanto ao tipo de polinização mais favorável à região, quantificar o desenvolvimento do fruto por planta polinizada, considerando a polinização com foco no objetivo deste trabalho, discutir as implicações dos resultados obtidos dentro do contexto da polinização na agricultura familiar e propor estratégias de manejo para o uso do melhor método de polinização.

\section{FUNDAMENTAÇÃO TEÓRICA}

\section{Passiflora edulis sims f. flavicarpa Degener}

A fruticultura é, atualmente, um dos segmentos mais importantes da agricultura brasileira, respondendo por $25 \%$ do valor da produção agrícola nacional. Nos últimos anos, aumentou sua área a uma taxa inesperada, ampliando suas fronteiras em direção à região nordeste, onde condições de luminosidade, umidade relativa e temperatura são mais favoráveis do que nas regiões Sul e Sudeste (Lacerda et al., 2004).

O maracujazeiro é originário da América Tropical, com mais de 150 espécies dentro da família Passifloraceae, utilizadas para produção e consumo humano (SABIÃO et al. 2011).

Os componentes desta família apresentam uma série de características morfológicas, tais como, flores axilares e solitárias, hermafroditas, brancas com franja roxa, gavinhas auxiliares, glândulas extraflorais ou nectários, folha alterna, coroa de estaminódios, androginóforo e sementes ariladas (CASTRO, 2012). Desta forma há um interesse pela beleza exótica de suas flores, com formato e colorido peculiar, o que viabiliza sua utilização na linha do agronegócio de plantas ornamentais (SANTOS et al., 2012). Além disso, seu cultiv o também é feito para fins medicinais, extraindo substâncias químicas de propriedades farmacêuticas como a passiflorina ou maracujina (BRITTO, 2013).

No Brasil, Passiflora edulis Sims (maracujá azedo, maracujá amarelo, 'maracuya') é encontrado em mais de $90 \%$ dos pomares. Outras espécies cultivadas no País incluem P.alata 
Curtis (maracujá-doce, maracujá-açu, maracujá mamão), P. setacea DC (maracujá do sono, maracujá do cerrado, maracujá pérola, maracujá sururuca, maracujá sururuca, maracujá de cobra) e P. cincinnata Mast . (maracujá do mato, maracujá da caatinga) que também atingem um nível comercial como árvore frutífera. Além disso, outras espécies como P. edulis Sims f. edulis (maracujá roxo nativo), P. nitida Kunth (maracujá suspiro, maracujá do cerrado), P. quadrangularis L. (maracujá gigante, 'badea', maracujá de quilo) e P. maliformis L. ('cholupa', 'granadilla de piedra ') são cultivadas local ou domesticamente. Outra oferta de cadeia que ganha força no Brasil é o uso de híbridos interespecíficos para fins ornamentais, já sendo uma tradição em alguns países europeus (FALEIRO et al., 2015).

A cultura do maracujazeiro tem um grande valor econômica para o Brasil, sendo que o maracujazeiro-azedo, Passiflora edulis Sims f. flavicarpa Deg, é a principal Passifloraceae cultivada (MELETTI, 2011). A cultura desenvolve-se melhor em locais onde a temperatura se situa entre 23 e $25{ }^{\circ} \mathrm{C}$, a umidade relativa em torno de $60 \%$, com fotoperíodo superior a 11 horas diárias (LIMA;BORGES, 2002).

As flores do maracujá amarelo apresentam grande valor ornamental, pois suas flores apresentam tamanho grande, coloridas, e originalidade nas formas. Segundo PEIXOTO (2005), a cultura do maracujazeiro apresenta grande diversidade e exploração em relação ao seu potencial paisagístico.

Segundo Vieira et al. (2010), o maracujazeiro possui características únicas que o difere das outras plantas frutíferas, as estruturas de suas flores é dependente de polinização natural, relizado pelos Xylocopa spp ou a polinização manual.

\section{Polinização}

A polinização, transposição dos grãos de pólen das partes masculinas para as partes femininas das flores, é um serviço ecossistêmico fundamental para reprodução da maioria das plantas e manutenção dos ecossistemas agrícolas e naturais em todo o planeta, podendo ser realizada naturalmente através do vento, água e principalmente através de animais, onde as abelhas são consideradas as mais eficientes (CHAM, et.al., 2017).

Nas passifloras, a polinização influencia a frutificação, seja por ação de agentes polinizadores (insetos), seja através da polinização artificial, sendo a diferença do percentual de pegamento pelos dois métodos, segundo Oliveira e Ruggiero (2005), devido ao número de polinizadores presentes no local do cultivo.

Polinização é a transferência de grãos de pólen entre flores de órgãos masculinos e femininos das flores, um processo importante para a reprodução das plantas que resulta na 


\section{EFICIÊNCIA E VINGAMENTO DO MARACUJÁ AMARELO}

formação de frutos e sementes, é realizada tanto por animais, vento, água ou até mesmo participação do homem. A maioria das plantas, cultivadas ou nativas, é polinizada por animais e insetos, e depende destes para sua reprodução (Roubik, 2018)

\section{Polinização aberta}

Os dispersores de pólen são denominados polinizadores, e têm um papel crucial no sucesso reprodutivo das plantas com flores e, portanto, na diversidade vegetal (Ollerton et al. 2011).

Para a agricultura o serviço de polinização, aproveitado gratuitamente pelas abelhas, é importante economicamente, por proporcionar frutos e sementes de melhor qualidade, garantindo assim uma maior renumeração ao produtor. Para floresta os interesses estão na manutenção de diversidade genética, preservação de vegetações nativas, e de animais que se alimentam e habitam nestes ambientes (POTTS et al., 2010).

Os polinizadores são os vetores que funcionam como intermediários nesse processo de reprodução transferindo o pólen das anteras para os estigmas. Uma polinização bem feita está diretamente ligada a um melhor rendimento da cultura agrícola, podendo não só levar ao aumento no número de sementes, vagens ou frutos vingados, como também melhorar a qualidade dos frutos (tamanho, peso, aparência, sabor e até elevar os valores nutritivos e o tempo de prateleira) e sementes (percentual de germinação e teor de óleos), além de influenciar positivamente em outras características de importância agronômica, tais como a antecipação e a uniformização no amadurecimento dos frutos, diminuindo as perdas na colheita (Freitas et al. 2016).

Para a agricultura o serviço de polinização, realizado gratuitamente pelas abelhas, é importante economicamente, por proporcionar frutos e sementes de melhor qualidade, garantindo assim uma maior produtividade ao produtor. Para vegetação silvestre os interesses estão na manutenção de diversidade genética, preservação de vegetações nativas, e de animais que se alimentam e habitam nestes ambientes (POTTS et al., 2010).

Para Freitas (2015), em alguns casos, o fato das abelhas mamangabas não encontrarem néctar suficiente em cada flor do maracujá, pode ser benéfico, fazendo com que elas coletem em mais flores do que o normal, ajudando a aumentar a polinização e beneficiando a eficiência da cultura toda. Esse fato, acontece por conta de um trabalho antes realizado por outras abelhas, conhecidas como irapuã, da espécie Trigonaspinipes, ou a Apis Melifera, que fazem furos na sustentação dos botões das flores, atingindo a câmara nectarífera acarretando na perda de parte do néctar. Logo, nesse caso, o néctar que a irapuã coleta, não prejudica a funcionalidade do 
processo e sim ajuda, já que a mamangaba deve assim polinizar mais flores do maracujá. E o furo feito por elas, nas flores para retirarem o néctar, não afeta a parte vascular da flor, e não ocorre perda ou queda da mesma por isso. Essa ação é benéfica no maracujazeiro-amarelo.

As Passifloras são dependentes da polinização cruzada para a formação do fruto, devido a sua morfologia floral. Apesar de a flor ser completa em maracujazeiro-amarelo, ocorre autoincompatibilidade (SUASSUNA et al., 2003).

\section{Xylocopa spp}

Entre os animais polinizadores, as abelhas são consideradas as mais eficientes, possuem diversas características comportamentais e adaptações morfológicas que as qualificam para essa definição, como constância floral, presença de pêlos e estruturas especiais para coleta ou transporte de pólen, néctar ou outros recursos florais ( COELHO, 2017).

A polinização no maracujazeiro é realizada pela abelha Bombus, Xylocopa, Euglossa e Centris, são abelhas grandes e atraentes e no Brasil, conhecidas com o nome de mamangabas, mamangás, mangangavas, mangavas, mangangás, mamangavas ou abelhas carpinteiras (Freitas, 2009) e, segundo Vieira et al. (2010), a importância dessas abelhas, especificadamente a Xylocopa, no pomar tem ligação direta com o lucro, pois sem a polinização correta, as flores não produzem os frutos.

Abelhas do gênero Xylocopa são consideradas as mais eficientes na polinização do maracujá, onde são criadas com facilidade em ninhos armadilhas, facilitando o manejo nas áreas da cultura (Chaves-Alves et al., 2011). Elas possuem o tamanho ideal e são efetivas para realizar a polinização cruzada, da qual o maracujá é dependente. As mamangabas, também são conhecidas como abelhas carpinteiras e auxiliam no aumento da produtividade do maracujá de maneira indispensável.

Uma série de fatores tem levado à redução no número de mamangavas na cultura do maracujazeiro, com altas perdas de produtividade da cultura. A diminuição da cobertura vegetal próxima às áreas cultivadas, falta de locais adequados para nidificação, ausência de espécies silvestres nos plantios que funcionem como fonte de alimento e o uso de defensivos agrícolas e o desmatamento vêm contribuindo para reduzir as populações dessas abelhas nos plantios comerciais para assegurar os níveis de polinização adequados (FREITAS \& OLIVEIRA FILHO, 2001).

\section{Polinização artificial}




\section{EFICIÊNCIA E VINGAMENTO DO MARACUJÁ AMARELO}

Devido ao aumento das ações antrópicas e consequentemente perda da qualidade ambiental, o decaimento das abelhas tem se tornado uma preocupação mundial (POTTS et al, 2010). Pesquisas incentivadas pela Iniciativa Internacional de Polinização (IPI), avaliaram 224 tipos de alimentos em 156 países sendo constatado que os polinizadores são necessários para produção de $35 \%$ daqueles e por até $40 \%$ pelo suprimento global de micronutrientes como a vitamina "A". No Brasil em um grupo de 141 culturas pesquisadas, 85 mostraram-se dependente de polinização (IMPERATRIZ; JOLY, 2017).

Uma quantidade de fatores tem levado à redução no número de mamangavas nos pomares de maracujá, com consequentes perdas de produtividade da cultura. A diminuição da cobertura vegetal próxima às áreas cultivadas, falta de locais adequados para nidificação, ausência de espécies silvestres nos plantios que funcionem como fonte de alimento e o uso excessivo de defensivos agrícolas vêm contribuindo para reduzir as populações dessas abelhas nos plantios comerciais para assegurar os níveis de polinização adequados (CAMILLO, 2000; FREITAS \& OLIVEIRA FILHO, 2001). Como solução, para tornar a cultura economicamente viável, a polinização manual vem sendo utilizada em todo o país, aumentando

\section{METODOLOGIA}

A pesquisa foi desenvolvida no município de Codó-MA, localizado na mesorregião do Leste Maranhense, com as seguintes coordenadas geográficas: $4^{\circ} 26^{\prime}$ 51" latitude Sul; $43^{\circ} 52^{\prime}$ 57" longitude Oeste de Greenwich. O clima da região é o Sub-Úmido do tipo C2 e Sub-úmido Seco do tipo $\mathrm{C} 1$. As temperaturas médias anuais variam de $26^{\circ} \mathrm{C}$ e $27^{\circ} \mathrm{C}$, com precipitação média anual de $1.100 \mathrm{~mm}$.

O locus da pesquisa tem área de $1248 \mathrm{~m}^{2}$, pomar com seis meses de desenvolvimento através da condução espaldeira vertical com espaçamento de $4 \mathrm{~cm}$ entre fileiras e $3 \mathrm{~cm}$ entre plantas e irrigação por gotejamento. $\mathrm{O}$ inseto polinizador envolve mamangavas presente no pomar.

Foram avaliadas 54 plantas de maracujá amarelo seguindo os tratamentos;

I. Flores livres (testemunha);

II. Flores cobertas com método artificial (utilização de dedeiras de flanela e cobertura das flores);

III. Flores livres com o método natural mais artificial (sem cobertura).

O experimento foi realizado na comunidade Associação dos Trabalhadores Rurais Boa União, localizada na região do bairro Trizidela, zona rural (Barro Branco), que fica a $10 \mathrm{~km}$ do centro da cidade de Codó 
Segundo o produtor local, as sementes são certificadas da flora Brasil e foram semeadas em sacos de polietileno de meio $\mathrm{kg}$ com a proporção de 1:3 esterco bovino e terra preta. Com 60 dias, foram transferidas para o local definitivo com uma área de 26x48m, onde ele colocou 160 gramas de calcário por cova e realizou a adubação de plantio segundo a recomendação técnica para o maracujá amarelo. Em seguida, conduziu a poda para formação das cortinas.

Figura 1: saco usado para ensacamento das flores

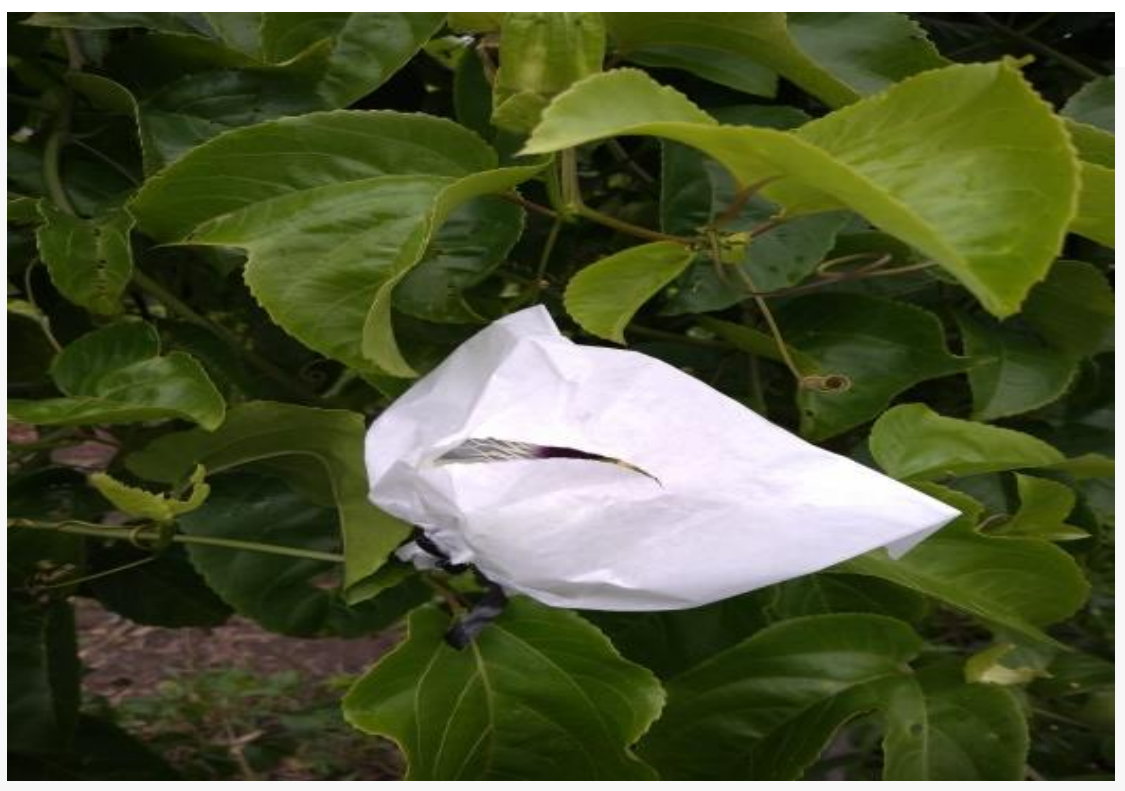

Fonte: Própria (2019)

Figura 2: fita colorida para marcar as flores

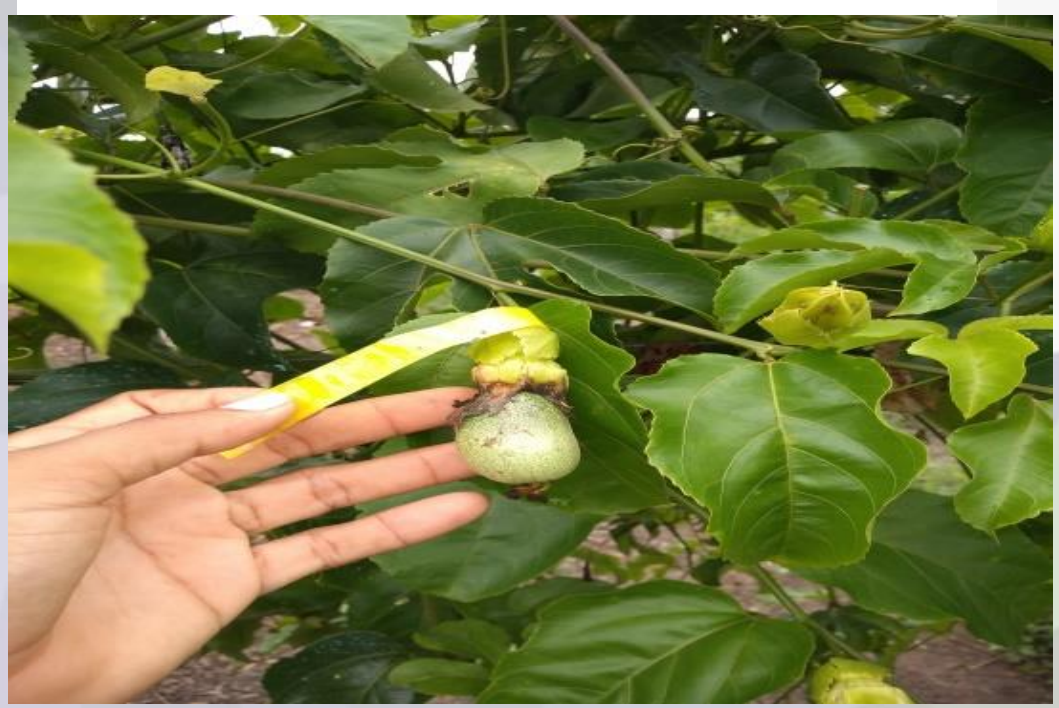

Fonte: Própria (2019)

Utilizou-se de alguns manejos, como podas, adubação de cobertura e aplicação de fungicida à 
base de sulfato de cobre para combater a antracnose (Colletotrichum gloeosporioides).

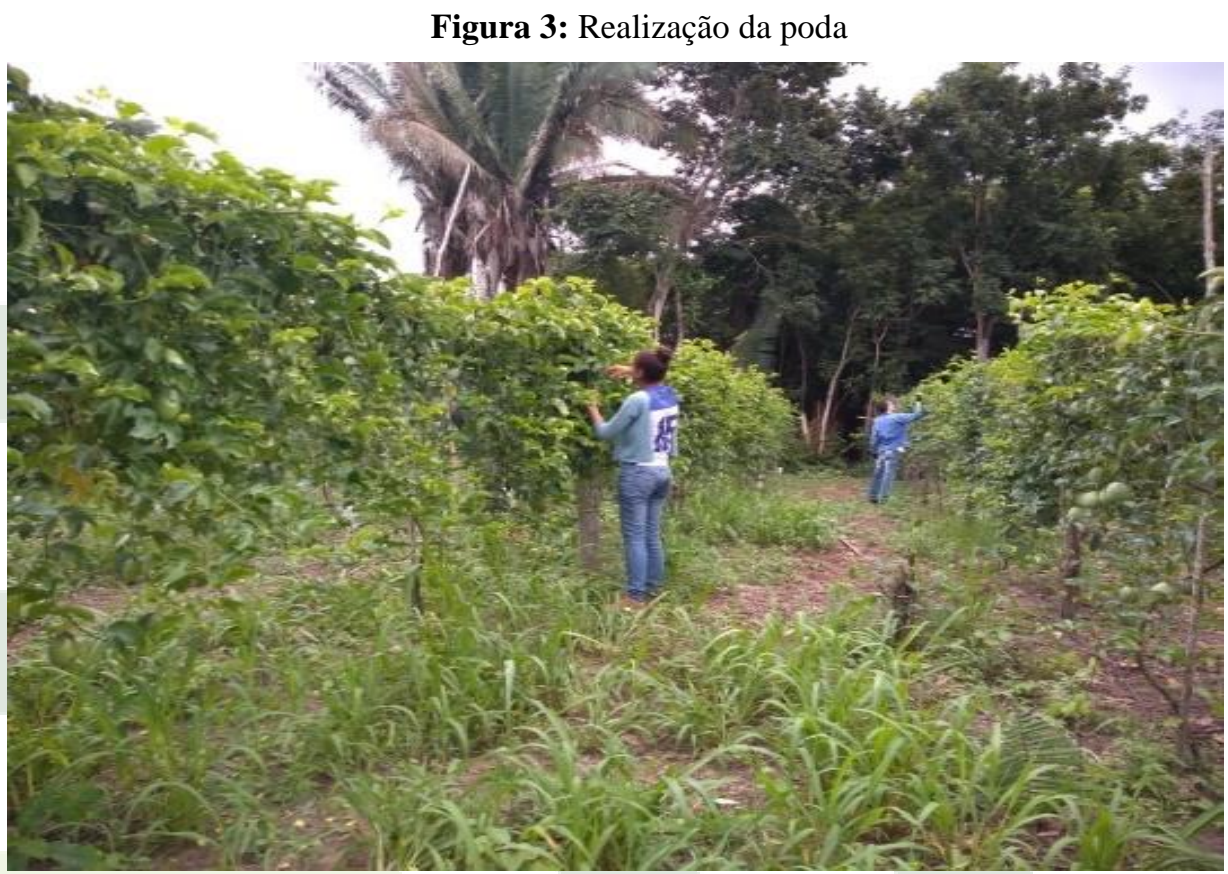

Fonte: Própria (2019)

Figura 4: Realização da adubação de plantio

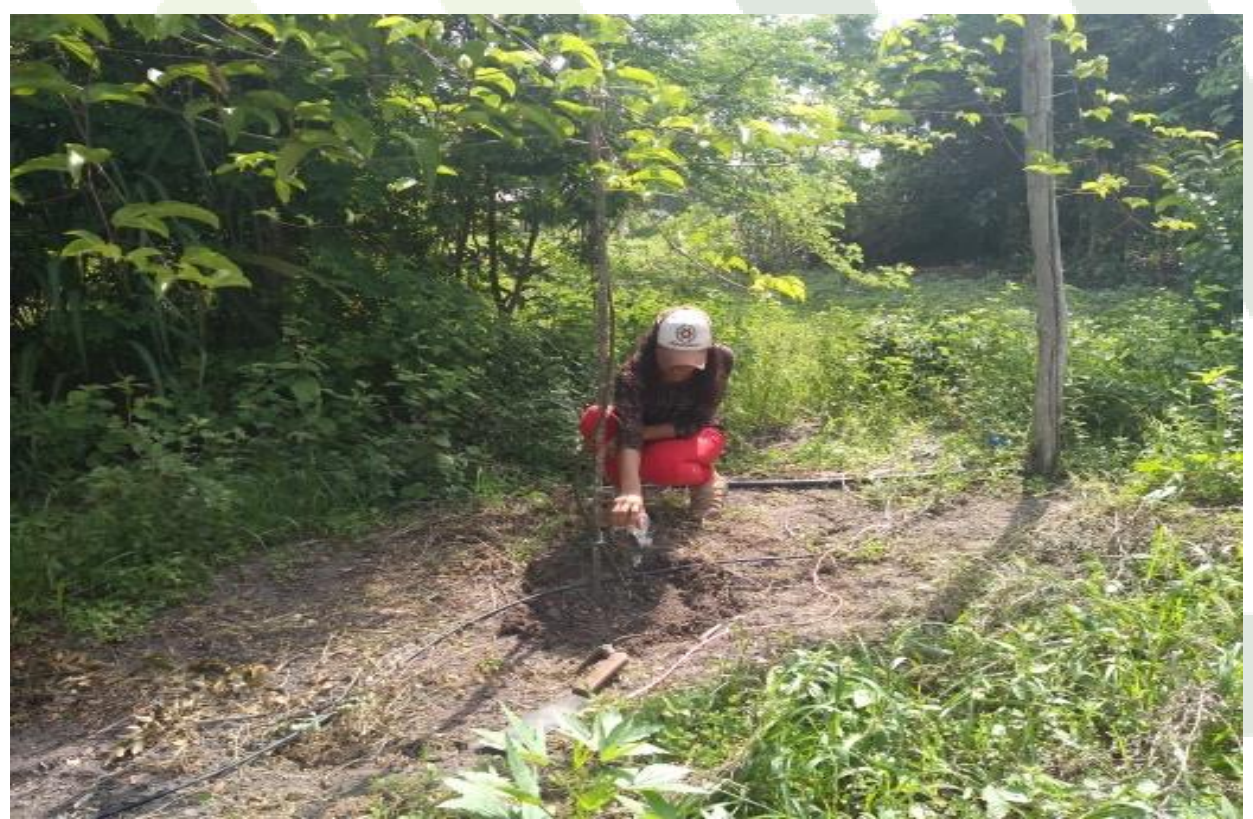

Fonte: Própria (2019)

A polinização foi realizada no período de Novembro de 2018 a Junho de 2019. Verificou-se a formação dos frutos, com 3 a 5 dias após a realização da polinização. Os dados 
coletados foi realizado a quantificação e porcentagem através do programa excel.

\section{RESULTADOS E DISCUSSÃO}

Esse trabalho foi realizado no periodo chuvoso dessa região, influenciando na eficiência da polinização, principalmente com o tratamento 1 (polinização aberta) que durante o experimento, a visita do inseto polinizador passou a não ser frequente por consequência da chuva. Os pólens das flores ficavam encharcados e/ou eram transportados junto às gotas de chuvas, dificultando, assim, o trabalho da polinização de todos os tratamentos, principalmente, das mamangavas que não faziam visitas no pomar nessa época.

Gráfico 1 :Total de frutos formados (FF), não formados (NF) e não encontrados (NE) a partir de um total de flores marcadas (FM) em função de diferentes tipos de polinização

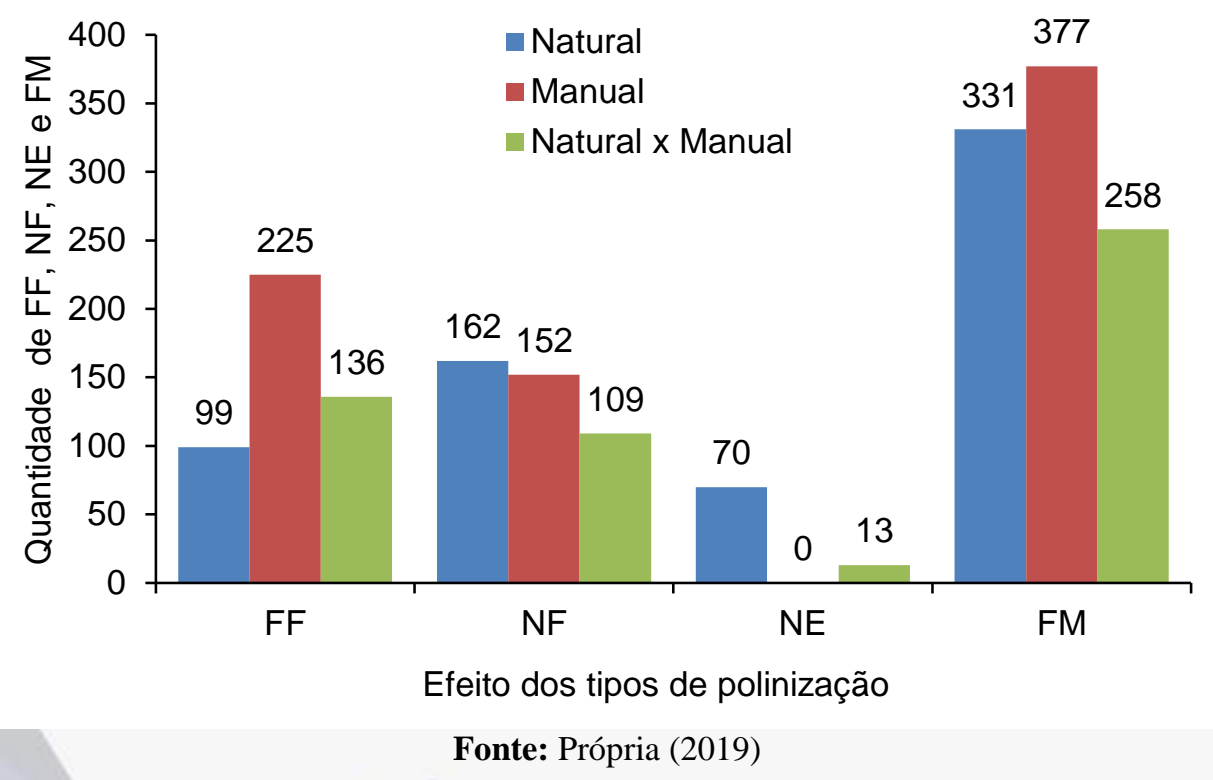

No gráfico 1, pode-se observar que o tratamento 1 (flores livres) em oposição aos tratamentos 2 e 3, obteve-se menor taxa de frutos formados e apresent

ou maior quantidade de frutos não formados, ou seja, o tratamento 1 resultou numa menor eficiência de frutificação.

O tratamento 2 apresentou a maior quantificação de frutos formados e uma menor taxa de frutos não formados, fazendo com que esse tratamento torne-se, estatisticamente, o melhor método da eficiência de polinização.

No tratamento 3, os frutos formados apresentaram maior quantificação do que dos frutos não formados. Esse tratamento, apesar dos resultados satisfatórios, esperava-se que fosse o melhor método para eficiência do maracujá quanto ao tipo de polinização, mas como realizavase a polinização manual somente quando se encontrava o pólen que o inseto deixava, pode ter 


\section{EFICIÊNCIA E VINGAMENTO DO MARACUJÁ AMARELO}

acontecido que essas flores tenham feito a fertilização antes de receber o reforço ( polinização manual), e eventualmente o inseto deixa pouco pólen em comparação com a polinização manual. Assim, os frutos não se desenvolviam totalmente (sem semente) e/ou caiam.

Enquanto a quantificação de flores marcadas para o tratamento 2, fez-se uma maior marcação durante o experimento por ser um tratamento mais controlado. Como consequência, não houve flor não encontrada. Em seguida, o tratamento 1, onde fez-se apenas a marcação com a fita colorida e foi o tratamento que mais teve flores não encontradas. Por fim, o tratamento 3 obteve uma taxa pequena de flores não encontradas, também foi o método que teve uma menor quantificação de flores marcadas por ser um tratamento mais detalhado.

Segundo SAZIMA (1989), a polinização realizada pelas mamangavas é influenciada pelas condições climáticas

Segundo FREITAS e OLIVEIRA FILHO (2001), afirmam que a queda excessiva de flores e a consequente redução na frutificação podem ser causadas por pragas e doenças e/ou desequilíbrio ambiental, mas o principalmente por falta de polinização

A seguir, consta a análise dos resultados em porcentagem da eficiência da polinização quanto aos frutos formados e os não formados.

Gráfico 2 : Porcentagem de frutos formados (FF) e não formados (NF) em função de diferentes tipos de polinização

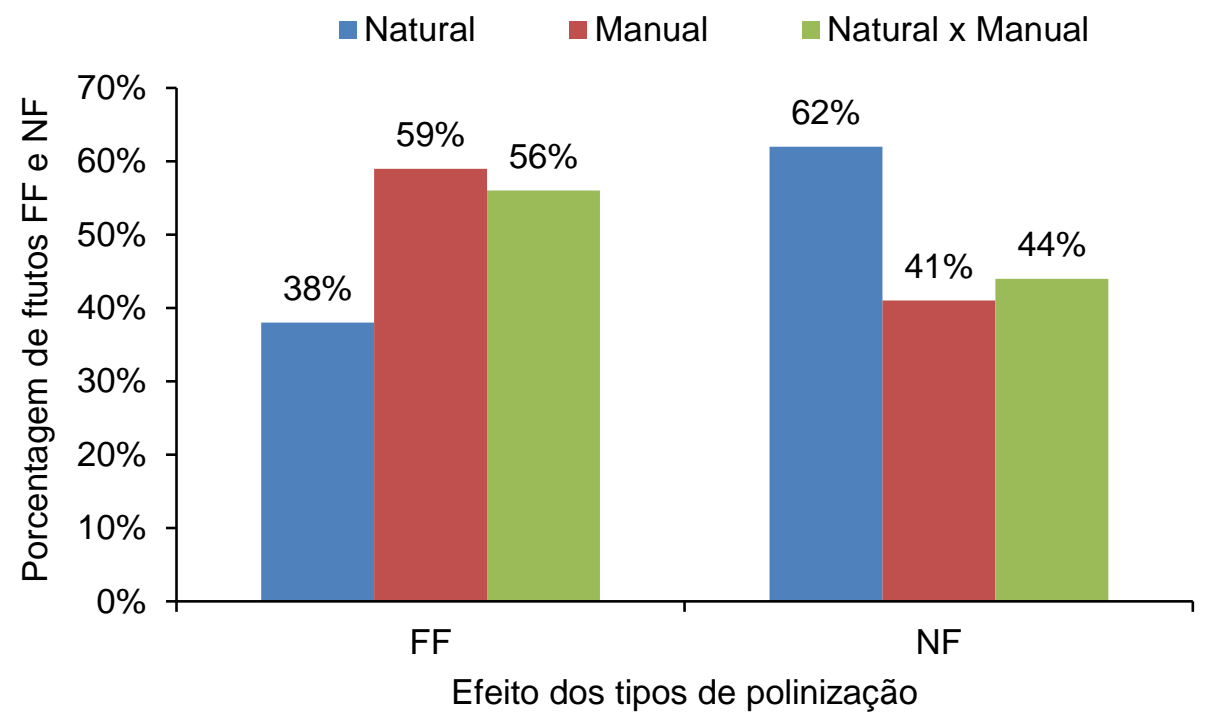

Fonte: Própria (2019)

No gráfico 2, o tratamento 1 apresentou diferença de $3 \%$ entre os frutos formados e não formados, para o tratamento 2 a diferença foi de $18 \%$, enquanto o tratamento 3 , foi de $12 \%$.

O tratamento de polinização manual, nesse estudo, apresentou melhores resultados quanto à eficiência do maracujá amarelo em diferentes tipos de polinização, seguida do 
tratamento 3, que também apresentou bons resultados, enquanto o tratamento 1 apresentou diferença significativa entre os demais.

Como afirma Sousa (1994) que considera 30\% de frutificação um indicativo de boa polinização natural, embora esta porcentagem possa ser melhorada com a polinização artificial, testificando os resultados encontrados nos tratamentos 1 e 2 .

A florada diária do maracujazeiro, nesse experimento foi superior, apesar de ser uma pequena área. Os dois mamangavas presentes no pomar não conseguiam polinizar $80 \%$ das flores abertas e marcadas durante este trabalho como descrevem Teixeira (1994) e Camilo (2003). A carência destes polinizadores nativos foi apontada como um dos fatores responsáveis pela baixa produtividade de frutos em diversas regiões.

Apesar da importância das mamangavas para a polinização do maracujá, o número de abelhas que visitam os pomares brasileiros vem diminuindo a cada dia, como consequência da constante aplicação de defensivos agrícolas para combater pragas e doenças, além da redução das matas nativas em torno dos plantios, as quais representam locais de nidificação e fonte de alimento para as mamangavas (FREITAS; OLIVEIRA-FILHO, 2001).

Durante essa pesquisa na agricultura familiar, observamos que apesar da área cultivada ser reduzido o agricultor responsável pode ter uma produção de qualidade quando realizado alguns manejos básicos como poda, limpeza do pomar (retirada de frutos doentes e deformada), adubação de plantio para prevenir um eventual ataque pragas e doenças e inibir a formação de mais botões florais e principalmente a prevservação dos insetos polinizadores. Enquanto ao manejo da polinização manual, segundo o produtor local a produção aumentou significamente em relação a safra anterior, retornando assim todo o seu investimento.

\section{CONCLUSÕES}

A época da florada e clima são importantes para uma boa eficiência das polinizações, o método de polinização manual é eficaz e viável para agricultura familiar, seguida dos dois métodos manual e natural salientando que a polinização aberta ainda é a mais importante, o agricultor tem pomar saudável e elevada florada quando faz os manejos básicos e tem elevada produção e produtividade quando realizada a polinização manual

\section{REFERÊNCIAS}

AKAMINE, E. K.; GIROLAMI, G. Pollination and fruit set in the yellow passion fruit. Hawaii Agric. Exp. Stn., n. 39, p. 3-44, 1959.

BERNACCI, L.C.; CERVI, A.C.; MILWARD-DEAZEVEDO, M.A.; NUNES, T.S.; IMIG, 
D.C.; MEZZONATO, A.C. Passifloraceae in Lista de Espécies da Flora do Brasil. Jardim Botânico do Rio de Janeiro, 2015

CAMILLO, E. Polinização do maracujá. Ribeirão Preto: Ed. Holos, 2003. 44p.

Viana, B. F. (coord) 2006. O maracujá-amarelo e seus polinizadores na região do vale médio São Francisco: Manual do produtor. Salvador: Editora da Universidade Federal da Bahia

BRITTO, F. F. Progênies híbridas de maracujazeiros do cruzamento Passiflora cincinnata Mast. x Passiflora quadrangularis Linn. 2013. 152p. Dissertação (Mestrado em Agronomia) Universidade Estadual do Sudoeste da Bahia, Vitória da Conquista, BA.

CAMILLO, E. Polinização do maracujá. Ribeirão Preto: Holos, 2003. 44 p.

CHAM, K; TONELLI, C., SILVA, F. V.; BORGES, SILVA, F. V. Atual cenário da avaliação de risco de agrotóxicos para polinizadores no Brasil. Importância dos polinizadores na produção de alimentos e na segurança alimentar global - Brasília, DF: Centro de Gestão e Estudos Estratégicos, p. 69-74, 2017

Chaves, R.C., Junqueira, N.T.V., Manica, I., Peixoto, J.R., Pereira, A.V., Fialho, J.F. (2004) Enxertia de maracujazeiro-azedo em estacas herbáceas enraizadas de espécies de passifloras nativas. Revista Brasileira de Fruticultura, Jaboticabal, 26(1):120-123.

CAMILLO, E. Polinização do maracujazeiro: mamangavas x africanizadas. In: CONGRESSO BRASILEIRO DE APICULTURA, 13., 2000, Florianópolis. Anais... Florianópolis : Confederação Brasileira de Apicultura, 2000. 1 CD.

EMBRAPA CERRADOS. Maracujá: pesquisa e desenvolvimento. Disponível em: . Acesso em: 14 out. 2013 b.

FALEIRO, Fábio Gelape; JUNQUEIRA, Nilton Tadeu Vilela. Maracujá: o produtor pergunta, a Embrapa responde. Brasília, DF: Embrapa, 2016. 341 p.

FREITAS, B. M.; BONFIM, I. G. A. Meliponíneos e polinização: a abelha jandaíra e outros meliponíneos na polinização agrícola no semiárido. In: A abelha jandaíra no passado, no presente e no futuro. p. 213- 220, 2017.

FALEIRO, F. G.; JUNQUEIRA, N. T. V.; COSTA, A. M. Importância socioeconômica e cultura do maracujá. In: FALEIRO, F. G.; JUNQUEIRA, N. T. V.(Ed.) Maracujá: o produtor pergunta, a Embrapa responde. Brasília, DF :Embrapa, 2016. p. 16-21.

FREITAS J. P. X. et al. Avaliação de recursos genéticos de maracujazeiro-amarelo. Pesq. agropec. bras., v. 46, p. 1013-1020, 2011.

FREITAS, B.M.; OLIVEIRA FILHO J. H. Criação racional de mamangavas para polinização em áreas agrícolas. Fortaleza : Banco do Nordeste, 2001. 96p

FREITAS, B. M.; OLIVEIRA-FILHO, J. H. Criação racional de mamangavas para polinização em áreas agrícolas. Fortaleza: BNB, 2001. 96 p 
FALEIRO, Fábio Gelape; JUNQUEIRA, Nilton Tadeu Vilela. Maracujá: o produtor pergunta, a Embrapa responde. Brasília, DF: Embrapa, 2016. 341 p

GONÇALVES, J.S.; SOUZA, S.A.M. Fruta da paixão: panorama econômico do maracujá no Brasil. Informações Econômicas, São Paulo, v.36, n.12, p.29-35, dez 2006.

IMPERATRIZ-FONSECA, V. L; JOLY, C. A., Plataforma Intergovernamental de Biodiversidade e Serviços de Ecossistemas (IPBES). Importância dos polinizadores na produção de alimentos e na segurança alimentar global - Brasília, DF: Centro de Gestão e Estudos Estratégicos, p. 18-33, 2017.

JUNQUEIRA, K.P.; JUNQUEIRA, L.P.; ZACHARIAS, A.O.; SCARANARI, C.; FALEIRO, F.G. Cultivares. In: FALEIRO, F.G.; JUNQUEIRA, N.T.V. (Ed.). Maracujá: o produtor pergunta, a Embrapa responde. Brasília, DF: Embrapa, 2016. 341 p. (Coleção 500 perguntas, 500 respostas).

KOSCHNITZE, C.; SAZIMA, M. Biologia floral de cinco espécies de Passiflora $\boldsymbol{L}$. (Passifloraceae) em mata semidecídua. Revista Brasileira de Botânica, v. 20, n.2, p.119-126, 1997.

KEVAN, P., 1999, Pollinators as biondicators of the state of the environment: species, activity and diversity. Agri. Ecosys. Envir., 74: 373-393.

LACERDA, M.A.D.; LACERDA, R.D.; ASSIS, P.C. de O. A participação da fruticultura no agronegócio brasileiro. Revista de Biologia e Ciências da Terra, Campina Grande, v.4, n.1, 2004.

MELETTI, L.M.M. Avanços na cultura do maracujá no Brasil. Revista Brasileira de Fruticultura, Jaboticabal, Volume Especial, p.83-91, 2011 Revista Caatinga, Mossoró, v. 27, n. 1, p. 187 - 193, jan. - mar., 2014

LIMA, A.; BORGES, A. L. Solo e clima In: LIMA, A. (Ed.). Maracujá-produção: aspectos técnicos. Brasilia: Embrapa- SPI, 2002. p. 25-28.

MELETTI, L.M.M.; OLIVEIRA, J.C.; RUGGIERO, C. Maracujá. Jaboticabal: FUNEP, 2010. (Série Frutas Nativas, 6.)

MELETTI, L.M.M.; BRÜCKNER, C.H. Melhoramento Genético. In: BRÜCKNER, C.H.; PICANÇO, M.C. Maracujá:tecnologia de produção, pós-colheita, agroindústria, mercado. Porto Alegre: Cinco Continentes, 2001. p. 345-385.

MATSOMOTO, S. N.; SÃO JOSÉ, A. B. Fatores que afetam a frutificação do maracujazeiro amarelo. In: MATSOMOTO, S.N.; SÃO JOSÉ, A B. A cultura do maracujá no Brasil. Jaboticabal: FUNEP-UNESP, p.110-127, 1991.

MEDEIROS DE SIQUEIRA, KÁTIA MARIA, FEITOSA MARTINS, CELSO, PIEDADE KIILL, LÚCIA HELENA, TORRES SILVA, LAIANE, ESTUDO COMPARATIVO DA POLINIZAÇÃO EM VARIEDADES DE ACEROLEIRAS (Malpighia emarginata DC, MALPIGHIACEAE). Revista Caatinga [en linea] 2011, 24 (Abril-Junio) 
MATSOMOTO, S. N.; SÃO JOSÉ, A. B. Fatores que afetam a frutificação do maracujazeiro amarelo. In: MATSOMOTO, S.N.; SÃO JOSÉ, A B. A cultura do maracujá no Brasil. Jaboticabal: FUNEP-UNESP, p.110-127, 1991.

OLIVEIRA, J. C.; RUGGIERO, C. Espécies de maracujá com potencial agronômico. In: FALEIRO, F. G.; JUNQUEIRA, N. T. V.; BRAGA, M. F. (Eds.). Maracujá: germoplamas e melhoramento genético. Brasília, DF: Embrapa Cerrados, 2005. p. 141-158.

Ollerton, J., R. Winfree \& S. Tarrant. 2011. How many flowering plants are pollinated by animals? Oikos 120: 321-326.

OLIVEIRA FILHO, J.H.; FREITAS, B.M. Colonização e biologia reprodutiva de Xylocopa frontalis em um modelo de ninho racional. Ciência Rural, v.33, n.4, p.693-697, 2003.

Potts, S.G., J.C. Biesmeijer, C. Kremen, P. Neumann, O. Schweiger \& W.E. Kunin. 2010. Global pollinator declines: trends, impacts and drivers. Trends. Ecol. Evol. 25: 345-353.

PENTEADO FILHO, R. de C. Création de systèmes d'intelligence dans une organisation de recherche et développement avec la scientométrie et la médiamétrie. 2006.328 f. Tese (Doutorado) - Université du Sud, Toulon, 2006.

ROUBIK, D. W., 1995, Pollination of cultivated plants in the tropics. Rome, FAO Agriculture Services Bulletin No 118

SUASSUNA, T. M. F.; BRUCKNER, C. H.; CARVALHO, C. R.; BOREM, A. Selfincompatibility in passionfruit: evidence of gametophytic-sporophytic control. Theoretical and applied genetics, Berlin, v. 106, n. 2, p. 298-302, 2003

SAZIMA, I.; SAZIMA, M. Mamangavas e irapuás (Hymenoptera, Apoidea): visitas, interações e consequiências para polinização do maracujá (Passifloraceae). Revista Brasileira de Entomologia, São Paulo, v.33, n.1, p.109-118, 1989.

SABIÃO RR et al. 2011. Enraizamento de estacas de Passiflora nítida submetidas a diferentes concentrações de ácido indolbutírico (AIB). Rev. Bras. Frut. 33: 654-657

VIEIRA, Márcio et al. Plantio Misto de Eucalyptus spp. com leguminosas arbóreas fixadoras de nitrogênio. Floresta e Ambiente, v. 20, n. 1, p. 16-25, 2010. 
COSTA, et al.

INSTITUTO INTERNACIONAL VOCAÇÕES
[17]

SOCIEDADE 5.0: EDUCAÇÃO, CIÊNCIA, TECNOLOGIA E AMOR. RECIFE. V COINTER PDVAgro 2020 